\title{
The curcumin analog DM-1 induces apoptotic cell death in melanoma
}

Fernanda Faião-Flores $^{\mathrm{a}, \mathrm{b}}$, José Agustín Quincoces Suarez ${ }^{\mathrm{c}}$, Silvya Maria Stuchi-Engler ${ }^{\mathrm{d}}$, Vanessa Soto-Cerrato ${ }^{\mathrm{e}}$, Ricardo Pérez-Tomás ${ }^{e}$, Durvanei Augusto Maria ${ }^{\text {a* }}$

${ }^{a}$ Laboratory of Biochemistry and Biophysics, Butantan Institute, São Paulo, Brazil

${ }^{\mathrm{b}}$ Faculty of Medicine, University of São Paulo, São Paulo, Brazil

${ }^{c}$ Laboratory of Organic Synthesis, Bandeirante University of São Paulo, São Paulo, Brazil

${ }^{\mathrm{d}}$ Department of Clinical Chemistry \& Toxicology, School of Pharmaceutical Sciences, University of São Paulo, São Paulo, Brazil,

${ }^{\mathrm{e}}$ Department of Pathology and Experimental Therapeutics, Cancer Cell Biology Research Group, Universitat de Barcelona, Barcelona, Spain

*Corresponding author: Durvanei Augusto Maria

E-mail address: durvanei@usp.br; fernandafaiao@yahoo.com.br

Phone: +55 1137267222 extension: 2364; Fax: +55 1137261505.

Adress: 1500 Vital Brasil Avenue

zip code: 05503-900

Laboratory of Biochemistry and Biophysics, Butantan Institute

São Paulo, Brazil

Conflicts of interest: none

\section{Summary}

The main difficulty in the successful treatment of metastatic melanoma is that this type of cancer is known to be resistant to chemotherapy. Chemotherapy remains the treatment of choice and dacarbazine (DTIC) is the best standard treatment. The DM-1 compound is a curcumin analog that possesses several curcumin characteristics, such as antiproliferative, antitumor and antimetastatic properties. The objective of this study was to evaluate the signaling pathways involved in melanoma cell death after treatment with DM-1 compared to the standard agent for melanoma treatment, DTIC.

Cell death was evaluated by flow cytometry for annexin $\mathrm{V}$ and iodide propide (PI), cleaved caspase 8 and TNF-R1 expression. Hoechst 33342 staining was evaluated by fluorescent microscopy; lipid peroxidation (LPO) and cell viability (MTT) were evaluated by colorimetric assays. The antiproliferative effects of the drugs were evaluated by flow cytometry for cyclin D1 and Ki67 expression. Mice-bearing B16F10 melanoma were treated with DTIC, DM-1 or both therapies.

DM-1 induced significant apoptosis as indicated by the presence of cleaved caspase 8 and an increase in TNF-R1 expression in melanoma cells. Furthermore, DM-1 had antiproliferative effects in this same cell line. DTIC caused cell death primarily by necrosis, and a smaller melanoma cell population underwent apoptosis. DTIC induced oxidative stress and several physiological changes in normal melanocytes, whereas DM-1 did not 
significantly affect the normal cells. DM-1 antitumor therapy in vivo showed tumor burden decrease with DM-1 monotherapy or in combination with DTIC, besides survival rate increase.

Altogether, these data confirm DM-1 as a chemotherapeutic agent with effective tumor control properties and a lower incidence of side effects in normal cells compared to DTIC.

Keywords: Melanoma, Dacarbazine (DTIC), DM-1, Curcumin analog, Apoptosis, synergism

\section{Introduction}

Metastatic melanoma is characterized by a high mortality rate [1]. This type of skin cancer has traditionally been difficult to treat because of its known universal resistance to standard chemotherapy [2]. Early stage disease can often be cured by surgery; however, unresectable cancer must be treated with systemic therapy. Although a greater percentage of patients are diagnosed with early stage disease compared to previous years, the death rate from unresectable melanoma continues to rise [3].

Dacarbazine (DTIC) is still considered the standard first-line treatment despite the lack of any evidence of this drug improving overall survival [4]. This is because no other single agent or combination of agents have demonstrated superiority to DTIC in terms of survival prolongation, even drugs associated with higher response rates [5]. Some oncoprotein-targeted drugs are promising as future cancer treatments; however, complete clinical responses to these drugs are rare [6].

In recent years, some pharmacological approaches have led to new therapy options including immune modulators like anti-CTLA4 or BRAF inhibitors like vemurafenib, which showed increased overall survival [78]. On the other hand, these new agents have some limitations and for this reason, classical chemotherapeutic drugs still remain in the therapy, especially as combinations of different treatment options aiming have to be focused on in order to find better responses in the melanoma treatment. This unsatisfactory treatment outcome encourages additional studies on novel therapeutic molecules, delivery systems and combination therapies for melanoma [9].

Curcumin has long been known as a chemo-preventive and chemotherapeutic agent, and in vivo studies with curcumin have demonstrated decreased tumorigenesis in many organs [10], including antiproliferative effects in melanoma [11]. Because of its lack of toxicity, there has been increasing interest in further studies with curcumin [12,13]. Unfortunately, its poor absorption undermine its clinical potential [14].

DM-1 is a curcumin analog and has previously been studied in animal models, such as melanoma and Ehrlich ascites tumor in mice. This compound is a powerful antitumor agent with both antimetastatic and antiproliferative activities $[15,16]$. Its pharmacological activity is restricted primarily to tumor tissue, with minimal side effects on the normal surrounding tissue.

The objective of this study is to compare the effectiveness of the chemotherapeutic compounds, DTIC and DM-1 in melanoma cells, their effects on cell death pathways and their side effects on normal cells.

\section{Materials and methods}

\section{Cell lines and culture conditions}


The murine melanoma cell line, B16F10, and the human melanoma cell line, A375, were purchased from the American Type Culture Collection (Manassas, VA). These cells were grown in $75 \mathrm{~cm}^{2}$ flasks with DMEM (Cultilab, SP, Brazil) supplemented with 10\% heat-inactivated fetal bovine serum (Cultilab), 2 mM Lglutamine (Sigma Chemical Company, USA) and $0.1 \mathrm{~g} / \mathrm{mL}$ streptomycin (FontouraWyeth AS, USA). Primary cultures of skin cells (melanocytes) were obtained from the foreskins of University Hospital (Hospital Universitário - HU-USP) patients. This project has undergone review and approval by the Ethics Committee of HU (HU no. CEP Case 943/09). The melanocytes were maintained in 254CF media (SKU \# M-500-254CF; Cascade Biologics, USA) supplemented with human melanocyte growth supplement (HMGS - SKU \# S-002-5; Cascade Biologics) as previously described [17]. The cells were grown at $37^{\circ} \mathrm{C}$ in a $5 \% \mathrm{CO}_{2}$ atmosphere.

\section{DM-1: Sodium 4-[5-(4-hydroxy-3-methoxyphenyl)-3-oxo-penta-1,4-dienyl]-2-methoxy-phenolate}

Dried sodium ethanolate $(0.01 \mathrm{~mol})$ was mixed with 1,5-bis(4-hydroxy-3-methoxyphenyl)-1,4pentadien-3-one [18] (0.01 mol; $3.26 \mathrm{~g})$ at a 1:1 molar ratio and stirred at room temperature under anhydrous reaction conditions followed by solvent rotoevaporation until solidification. The compound $\mathrm{C}_{19} \mathrm{H}_{17} \mathrm{O}_{5} \mathrm{Na}$, has a molecular weight of $348 \mathrm{~g}$. Results of the structural characterization of the isolated compound were consistent with those described previously by our group $[19,20]$.

\section{Cell treatment for MTT and LPO assays}

B16F10 melanoma cells, A375 melanoma cells and melanocytes were seeded in 96-well plates at a density of $10^{5}$ cells $/ \mathrm{mL}$ and allowed to grow for $24 \mathrm{~h}$. They were then treated with different concentrations of DTIC (Evolabis, Brazil) or DM-1 diluted in $0.9 \% \mathrm{NaCl}$ at concentrations ranging from 2560 to $5 \mu \mathrm{M}$. As a control, the cells were treated with the diluent only.

\section{Cell viability assay (MTT assay)}

After $24 \mathrm{~h}$ of treatment with DTIC or DM-1, $10 \mu \mathrm{M}$ MTT (Sigma Chemical Company, USA) [21] was added to each well for an additional $4 \mathrm{~h}$. The blue MTT formazan precipitate was dissolved in $100 \mu \mathrm{L}$ DMSO. The absorbance at $540 \mathrm{~nm}$ was measured with a multi-well plate reader. The cell viability was expressed as a percentage of the control cells, and the data are shown as the mean value \pm s.d. (standard deviation) of three independent experiments.

\section{Lipid Peroxidation (LPO)}

The oxidative stress on unsaturated lipids in the cell membranes was evaluated by determining the amount of malondialdehyde (MDA), which is the final product of fatty-acid peroxidation. MDA reacts with thiobarbituric acid (TBA) to form a colored complex. The thiobarbituric acid reactive substances (TBARS) were quantified by spectrophotometric determination (LPO method) [22]. The supernatants from the samples were obtained after drug treatment under the same conditions of MTT assay.

\section{Cell treatment for flow cytometry analysis}


B16F10 cells and melanocytes were seeded in 24-well plates at a density of $10^{5}$ cells $/ \mathrm{mL}$ and allowed to grow for $24 \mathrm{~h}$. Each cell line was treated with the Inhibitory Concentration $50 \%\left(\mathrm{IC}_{50}\right)$ for each compound for 6 h.

\section{Mitochondrial membrane electric potential $(\Delta \psi \mathrm{m})$ assessment by flow cytometry}

Rhodamine 123 is a fluorescent cationic dye that binds to polarized mitochondrial membranes and accumulates as aggregates in the mitochondria of normal cells [23]. This agent binds only to metabolically active mitochondria, resulting in fluorescence emission.

After treatment, cells in the supernatant and the adherent cells were pelleted by centrifugation at $1800 \mathrm{rpm}$ for $10 \mathrm{~min}$ and resuspended in $5 \mu \mathrm{L}$ Rhodamine $123(5 \mathrm{mg} / \mathrm{mL})$ for $30 \mathrm{~min}$ at $37^{\circ} \mathrm{C}$. The cells were then washed with phosphate-buffered saline (PBS) and resuspended in FACS buffer (FACSCalibur-Becton Dickinson, USA). The samples were analyzed for fluorescence using a FL-1H detector on a Becton Dickinson FACScan flow cytometer using the CellQuest software. Flow cytometry histograms were recorded, and the relative intensity of fluorescence was calculated as the mean of active mitochondria (viable cells) or inactive mitochondria (inviable cells) of the control and treated samples.

\section{Apoptosis analysis by flow cytometry}

Annexin $\mathrm{V}$ staining detects the translocation of phosphatidylserine from the inner to the outer cell membrane during early apoptosis, and propidium iodide (PI) can enter the cell during late-stage apoptosis and also stains dead cells [23].

After treatment, the cells in the supernatant and the adherent cells were washed with PBS and binding buffer (10 mM HEPES pH 7.5 containing $140 \mathrm{mM} \mathrm{NaCl}$ and $2.5 \mathrm{mM} \mathrm{CaCl}_{2}$ ) and stained with $1 \mu \mathrm{g}$ annexin $\mathrm{V}$ FITC (Santa Cruz Biotechnology, USA) and $18 \mu \mathrm{g} / \mathrm{mL}$ of propidium iodide (Sigma-Aldrich Corp.). Each sample was analyzed by flow cytometry using the FL-1 and FL-2 channels to distinguish the apoptotic, necrotic, and viable cell populations. The analysis was performed on a FACSCalibur flow cytometer using the CellQuest software (FACSCalibur; Becton Dickinson).

\section{Protein analysis by flow cytometry}

After treatment, the cells in the supernatant and the adherent cells were pelleted by centrifugation at 1800 rpm for 10 min and incubated with $1 \mu \mathrm{g}$ of specific anti-cyclin D1 (Santa Cruz, USA), anti-Ki67 (Dako, USA), anti-caspase 8 or anti-TNF-R1 receptor antibodies (tumor necrosis factor- $\alpha$ receptor) (Santa Cruz, USA) and 10 $\mu \mathrm{L} 0.1 \%$ Triton $\mathrm{X}-100$ for $1 \mathrm{~h}$ at $4^{\circ} \mathrm{C}$. Then, the samples received addition of $2 \mu \mathrm{L}$ anti rabbit IgG-Alexafluor488 (Invitrogen, USA) in untagged primary antibody coupled cells and incubated further in dark for 30-35 min. Excess fluorescence was then washed off with PBS. Subsequently, the cells were resuspended in FACS buffer. The samples were analyzed for fluorescence (FL-1 channel) on a Becton Dickinson FACScan flow cytometer using the Cell Quest software.

\section{Hoechst staining}

Cell nuclear morphology was evaluated by fluorescence microscopy following Hoechst 33342 DNA staining (Sigma-Aldrich Corp). A375 human melanoma cells were seeded in 24-well plates at a density of $10^{5}$ 
cells $/ \mathrm{mL}$ and were grown for $24 \mathrm{~h}$. This cell line was treated with the $\mathrm{IC}_{50}$ for either DTIC or DM-1 alone or a combination of $5 \mu \mathrm{M}$ DTIC $+5 \mu \mathrm{M}$ DM-1 for $24 \mathrm{~h}$. These concentrations were chosen in order to verify if the addition of DM-1 compound would allow the DTIC concentration decrease down to $10 \%$ of $\mathrm{IC}_{50}$ with the same efficacy in this cell type. The cells were washed with phosphate buffer saline (PBS), resuspended in $2 \mu \mathrm{g} / \mathrm{mL}$ Hoechst 33342 and incubated for $30 \mathrm{~min}$ at $37^{\circ} \mathrm{C}$ in the dark. Then, cells were then washed with PBS and examined under a Nikon fluorescent microscope.

\section{Inoculation of B16 melanoma cells in mice}

The murine B16F10 was cultivated in RPMI-1640 medium supplemented with $10 \%$ fetal bovine serum (FBS), $2 \mathrm{mM}$-Lglutamine, $1 \mathrm{mM}$ sodium pyruvate and $100 \mathrm{IU} / \mathrm{ml}$ of penicillin and $100 \mu \mathrm{g} / \mathrm{ml}$ of streptomycin (Invitrogen Inc, Carlsbad, USA). Cell suspensions were detached from plates with trypsin. After trypsin inactivation with $10 \%$ FBS, viable cells were counted by trypan blue dye exclusion. For tumor inoculation, $5 \times 10^{4}$ cells were suspended in $100 \mu \mathrm{l}$ of PBS and injected subcutaneously into the flank regions of C57BL/6J mice. Ten to fourteen days after inoculation the tumors became macroscopically apparent.

\section{In vivo antitumor activity}

Mice were inoculated with B16F10 melanoma cells as described above and were randomly allocated to four groups of 5 animals. The DM-1 compound and DTIC were administered by intraperitoneal way. The DM-1 compound was administered daily and its concentration was $83 \mu \mathrm{M}$ in $100 \mu \mathrm{L}$ of saline solution. This concentration was calculated considering the $\mathrm{IC}_{50}$ value determined in the in vitro assay.

On fourteen day counted from the initial inoculation day, four experimentation groups were used:

Control: five mice-bearing B16F10 melanoma were treated with $100 \mu \mathrm{L}$ of saline solution $0.9 \%$;

DTIC: five mice-bearing B16F10 melanoma were treated with $4.5 \mathrm{mg} / \mathrm{kg} / \mathrm{body}$ mass of DTIC [24] diluted in saline solution $0.9 \%$ every two days for a total of seven doses;

DM-1: five mice-bearing B16F10 melanoma were treated daily with DM-1 compound diluted in saline solution $0.9 \%$;

DTIC+DM-1: five mice-bearing B16F10 melanoma were treated daily with DM-1 compound diluted in saline solution $0.9 \%$ plus $4.5 \mathrm{mg} / \mathrm{kg} /$ body mass of DTIC every two days for a total of seven doses;

Tumor sizes were measured daily using a calipers-like instrument. The size measurement was converted to tumor volume by the equation: tumor area $=\Pi R^{2}$, where $\Pi$ was (length tumor + width tumor)/4 [25]. Necropsies were performed after 14 days of tumor inoculation. All animal experiments were carried out according to the regulations of the Ethical Committee for Animal Research at the Butantan Institute (479/09).

\section{Statistical analysis}

The values are expressed as the mean \pm s.d. The data were analyzed using a one-way analysis of variance (ANOVA). Significant differences in the means were determined using multiple comparisons with the Tukey-Kramer test at a significance level of $\mathrm{p}<0.05$. Any significant differences between the control and treated groups are indicated as $* * * \mathrm{p}<0.001, * * \mathrm{p}<0.01$, and $* \mathrm{p}<0.05$.

\section{Results}




\section{DM-1 decreases cell viability in melanoma cells}

To evaluate the cytotoxic effects of DM-1 and DTIC, B16F10 murine melanoma cells, A375 human melanoma cells and normal melanocytes were treated with different drug concentrations for $24 \mathrm{~h}$ and cell viability was determined by MTT assay.

Consistent with the results of Henmi and co-workers [26], the chemotherapeutic agent DTIC, had high $\mathrm{IC}_{50}$ values in the $\mathrm{A} 375$ human melanoma cell line. For the B16F10 murine melanoma cells, this value was even higher. DM-1 had greater cytotoxic effects that were approximately 46- and 8-fold higher in the murine and human melanoma cell lines, respectively, compared to DTIC. Treatment of the normal melanocytes showed no significant differences between the $\mathrm{IC}_{50}$ values of the two compounds (Table 1). Altogether, these results indicate that DM-1 has a higher potency and selectivity for cancer cells, whereas DTIC acts similarly in both cancer and normal cells.

Please insert Table 1 here.

\section{DM-1 induces cell death by apoptosis in melanoma cells}

As observed above, DTIC and DM-1 treatment of B16F10 cells induced a significant decrease in cell viability. To discriminate the type of cell death triggered by these drugs, annexin $\mathrm{V}$ flow cytometry analysis was performed. Four different populations of cells were easily identified: unlabeled viable cells, annexin V positive cells (early apoptotic), PI positive cells (necrotic) and annexin V and PI positive cells (late apoptotic).

In our experiments, DTIC treatment increased the percentage of necrotic B16F10 cells by approximately 75\%. Conversely, DM-1 significantly increased the percentage of cells undergoing late apoptosis, to approximately $90 \%$ after $6 \mathrm{~h}$ of treatment (Fig. 1 A-D). In normal melanocytes, these two types of cell death were not significantly changed with either treatment (Fig. 1 E-H).

\section{Please insert Figure 1 here.}

Mitochondrial membrane potential $(\Delta \psi \mathrm{m})$ changes are an additional indication of apoptosis because $\Delta \psi \mathrm{m}$ contributes to the process that facilitates the exit of many apoptogenic factors to the cytosol. As shown in fig. 2 (A-C), the electric mitochondrial membrane potential of B16F10 melanoma cells was decreased after $6 \mathrm{~h}$ of treatment with DTIC and DM-1. Both treatments induced a significant reduction in $\Delta \psi \mathrm{m}$; however, DM-1 caused a $65 \%$ decrease in viable cells and/or active mitochondria, whereas DTIC induced only a $12 \%$ decrease in viable cells and/or active mitochondria compared to the untreated cells.

Melanocytes treated with DTIC showed a moderate decrease in mitochondrial electric potential. In addition, DM-1 treatment did not change this potential in normal cells (Fig. 2 D-F), demonstrating DM-1 specificity for cancer cells.

Please insert Figure 2 here. 
Finally, nuclear morphological changes were examined because they are another classical feature of apoptosis. The cells were examined under fluorescence microscopy after Hoechst 33342 staining to confirm apoptotic cell death. The apoptotic nuclei were distinctively marginated and fragmented when observed under the fluorescent microscope.

The control cells were highly confluent and displayed regular nuclear structure (Fig. 3 A). After DTIC treatment $\left(\mathrm{IC}_{50}\right)$, a few of the A375 human melanoma cells showed 'bean-shaped' nuclei (Fig. 3 B). DM-1 treatment $\left(\mathrm{IC}_{50}\right)$ induced the formation of apoptotic bodies and nuclear condensation (Fig. $3 \mathrm{C}$ ).

The combination of DTIC and DM-1, each at lower concentrations $(5 \mu \mathrm{M})$, induced the formation of apoptotic bodies, 'bean-shaped' nuclei, highly condensed chromatin and nuclei with irregular clumps of dense chromatin (Fig. 3 D). These results suggest a synergistic effect between DTIC and DM-1.

Please insert Figure 3 here.

\section{Extrinsic apoptotic pathway activation}

Apoptosis can be induced by the extrinsic and/or the intrinsic (mitochondrial) pathway. Caspases represent a family of cysteine proteases that are common downstream effectors of apoptosis. The cleavage of caspase 8 indicates cell death initiated by the extrinsic apoptotic pathway [27]. The expression levels of several markers of this pathway, such as cleaved caspase 8 and TNF-R1, were evaluated after $6 \mathrm{~h}$ of DTIC or DM-1 treatment. Both treatments caused an increase of cleaved caspase 8 in the B16F10 melanoma cells; however, only DM-1 increased TNF-R1 levels (Fig 4 A and C). Notably, there was a moderate decrease in the level of cleaved caspase 8 in the melanocytes, but changes in the TNF-R1 were not observed. This indicates that the extrinsic apoptotic pathway is not activated in the normal melanocytes (Fig. 4 B and D).

\section{Please insert Figure 4 here.}

\section{Free radical production}

Oxidative stress causes cellular damage, which can lead to apoptosis. To evaluate whether DTIC and DM-1 induce oxidative stress in melanoma cells, free radical production was assessed by the evaluation of malondialdehyde production in the cytoplasmic membranes of B16F10 melanoma cells and melanocytes after drug treatment.

DTIC induced an approximately 10-fold increase in the amount of malondialdehyde in the B16F10 cells. Significant effects were observed until a concentration of $160 \mu \mathrm{M}$ (Fig. 5 A). By contrast, DTIC caused a doubling of malondialdehyde synthesis in normal melanocytes and a significant damage was observed with the majority of concentrations tested, up to $80 \mu \mathrm{M}$ (Fig. 5 B).

DM-1 treatment increased the malondialdehyde concentration by 130-fold in the B16F10 melanoma cell line and induced damage at all the concentrations tested (Fig. 5 C). Furthermore, DM-1 caused less damage than DTIC at the same concentrations in normal melanocytes. A moderate increase of malondialdehyde production was observed only for the two highest concentrations tested (Fig. 5 D).

\section{Please insert Figure 5 here.}




\section{DM-1 and DTIC have antiproliferative effects on melanoma cells, but not normal cells}

The antiproliferative effects of the drugs on the melanoma cells were evaluated by cyclin D1 and Ki67 protein expression. Type D cyclins, together with their CDK partners, form a key regulatory unit of the G1/S transition that is frequently impaired in neoplasia [28]. The Ki67 nuclear protein is expressed in proliferating cells and may be necessary to maintain cell proliferation. Ki67 has been used as a marker of cell proliferation in solid tumors [29].

Cyclin D1 levels were significantly decreased after DTIC $(\mathrm{p}<0.01)$ and DM-1 $(\mathrm{p}<0.001)$ treatment in B16F10 melanoma cells (Fig. 6 A). Conversely, this reduction was not observed in the normal melanocytes. In fact, these cells presented a slight increase in the expression of cyclin D1 after treatment (Fig. 6 B).

By contrast, Ki67 expression was significantly decreased after treatment of the melanoma cells with DTIC or DM-1, (Fig. 6 C). DM-1 did not modify expression of Ki67 in normal melanocytes; however, a moderate increase in expression of this marker was observed after DTIC treatment (Fig. 6 D).

\section{Please insert Figure 6 here.}

\section{In vivo DM-1 antitumor effect}

The DM-1 compound also showed in vivo antitumor activity. The cytotoxic effects were obtained with DM-1 compound administration alone or in combination with chemotherapeutic DTIC. The B16F10 melanomabearing mice without treatment (control group) showed a significant tumor area increase. The group receiving DTIC chemotherapy alone showed a $43 \%$ tumor burden decrease in comparison to the control group. The group treated with DM-1 compound alone and the group treated with both therapies showed 57\% and $63 \%$ tumor burden reduction, respectively, compared to control group (Figure 7A). Both groups treated with DM-1 compound showed better antitumor effects than DTIC monotherapy.

After 28 days of B16F10 melanoma cell inoculation, there were no live animals in the control group. In this same period, there were $40 \%$ of live mice treated with DTIC in monotherapy. The mice survival rate of both DM-1 groups (monotherapy or in combination with DTIC) was significantly increased in comparison to the control group or DTIC monotherapy, because in the end of 14 treatment days with DM-1, all mice remained alive (Figure 7B).

\section{Please insert Figure 7 here.}

\section{Discussion}

The incidence of melanoma continues to rise, and an estimated increase of $27 \%$ in new diagnoses was made in 2012. This is significantly greater than only 5 years ago [3]. This increase in incidence is due both to improved awareness leading to additional diagnoses and to life style changes that have resulted in an increase in sun exposure over the past decades. Moreover, melanoma has a known resistance to chemotherapy and this is related, in part, to defects in proapoptotic signaling [30].

The DM-1 compound showed $\mathrm{IC}_{50}$ values considerably lower than the currently used chemotherapeutic, DTIC. In addition, it induced injury to tumor cells at lower concentrations, and also caused oxidative damage in 
the B16F10 melanoma cell line at all concentrations tested (2560-5 $\mu \mathrm{M})$. DTIC showed similar levels of damage in only half the concentrations tested, and had less cytotoxic potential than DM-1. Furthermore, DTIC caused oxidative damage in the normal melanocytes at the same concentrations used for treating the melanoma cells. DM-1 caused oxidative damage only in the melanocytes treated with the two highest concentrations of drug. Pretreatment with different concentrations of another curcumin analog caused a significant decrease in the levels of TBARS and DNA damage in normal hepatocytes [31].

Reactive oxygen species (ROS) interact with biological molecules to produce toxic free radicals resulting in lipid peroxidation (LPO) and DNA damage [32]. Furthermore, LPO products, such as malondialdehyde, form adducts with cellular DNA. LPO can be defined as a cascade of biochemical events resulting from the action of free radicals on the unsaturated lipids of cell membranes. This generates primarily alkyl, peroxyl and alkoxyl radicals, leading to destruction of their structure, the failure of mechanisms that exchange metabolites and cell death. Therefore, LPO can be used as an indicator of cellular oxidative stress [33].

In non-apoptotic cells, most phosphatidylserine molecules are localized to the inner layer of the plasma membrane. However, in the annexin V assay, the translocation of phosphatidylserine residues from the internal layer to the outer face of the plasma membrane prior to the loss of membrane integrity is an indicator of apoptotic induction [23]. After DM-1 treatment, the majority of the B16F10 melanoma cells showed cell death by apoptosis, whereas cells treated with DTIC presented necrosis as the main type of cell death. In melanocytes, these effects were not observed.

Disruption of the $\Delta \psi \mathrm{m}$ is an early event associated with apoptosis and has been suggested to be one of several factors responsible for cytochrome c release [34]. Melanoma cells showed a significant decrease in the $\Delta \psi \mathrm{m}$ for both treatments. However, DTIC also caused this effect in normal melanocytes, thereby inducing changes in cell polarity and causing cell death.

Extrinsic and intrinsic apoptotic pathways have both been described [35]. The extrinsic pathway is initiated by binding of TNF-R1, CD95L/FasL or TRAIL to death receptors, the formation of death-inducing signaling complexes (DISC) and activation of the initiator caspases 8 and 10 [36]. By contrast, the intrinsic pathway is initiated by cellular and DNA damage and utilizes mitochondria particularly. Key events that occur when the intrinsic apoptotic pathway is activated are the depolarization of $\Delta \psi \mathrm{m}$ and mitochondrial outer membrane permeabilization (MOMP). This results in the release of mitochondrial factors, such as cytochrome c, AIF (apoptosis-inducing factor) and SMAC (second mitochondria derived activator of caspases) [37]. The initiator caspases 8,9 and 10 activate the downstream effector caspases 3,6 and 7, which cleave a large number of death substrates to initiate apoptosis [38].

DM-1 treatment induced an increase in TNF-R1 expression, in addition to significant activation of caspase 8. DTIC also induced moderate caspase 8 cleavage; however, there was no increase in TNF-R1 expression. Bill and coworkers also showed that a curcumin analog induced apoptosis through caspase 8 cleavage after $24 \mathrm{~h}$ of treatment. This compound also resulted in the loss of mitochondrial membrane potential in the melanoma cells [39].

Additionally, the morphological changes in the A375 human melanoma cells treated with DM-1 included the formation of apoptotic bodies and condensed chromatin, whereas the cells treated with DTIC presented with 'bean-shaped' nuclei when analyzed by Hoechst 33342 staining. However, the combination of both treatments, at appreciably lower concentrations, induced all of the above cited characteristics. It is known 
that the effects of DTIC can be improved by combination with other chemotherapeutic agents or new compounds [40]. Together with the annexin V data, it can be concluded that only a small population of cells treated with DTIC undergo apoptosis, whereas the majority die by necrosis. However, the results obtained with DM-1 indicate that DM-1 induces apoptosis in melanoma cells.

Cell cycle dysregulation is a fundamental process in tumor progression, and unregulated cell proliferation is a feature of malignant tumors. Cell proliferation and the cell cycle are regulated by the formation, activation, and degradation of a series of cyclins and cyclin-dependent kinase complexes. Cyclin D1, a G1 cellcycle protein, phosphorylates and inactivates the tumor-suppressor protein, retinoblastoma, and promotes the progression from G1 to $\mathrm{S}$ phase [41]. Increased proliferative activity of tumor cells is also associated with malignancy and is an important prognostic marker in many human cancers. Markers that are widely used to assess cell proliferation are the proliferating cell nuclear antigen and the Ki67 protein. The latter is a nuclear antigen synthesized throughout most of the cell cycle, except during the G0 and early G1 phases [42].

Cyclin D1 expression in melanoma cells was reduced after treatment with both DTIC and DM-1. This effect was the opposite of what was observed in the normal melanocytes. This could be explained as a proliferative response to injury caused by the treatments. These effects were partially observed for Ki67 expression. The melanoma cells had reduced expression of Ki67, whereas the melanocytes treated with DTIC showed a moderate increase in Ki67 expression. There were no significant changes in Ki67 expression in melanocytes treated with DM-1. Curcumin and some of its analogs also induce a decrease in cyclin D1 expression [43]. This way, the analogs, including DM-1, can be effective in regulating the cell cycle progression of tumor cells.

As action mechanism, the DM-1 compound induces cell cycle arrest by cyclin D1 and Ki67 decrease and apoptosis by free radicals production, TNF-R1 and cleaved caspase- 8 increase, as well mitochondrial electrical potential decrease. Furthermore, apoptosis was also confirmed by apoptotic bodies in human melanoma cell line. That is, the extrinsic and intrinsic apoptosis pathways were enabled by DM-1. DM-1 compound also induces Bcl-2 and Mcl-1 decrease, besides caspase 3, 9 and Parp cleavage (data not shown). DM-1 antitumor therapy in vivo showed tumor burden decrease with DM-1 monotherapy or in combination with DTIC, besides survival rate increase. Aggarwal and coworkers showed a decrease of approximately $30 \%$ in tumor burden after treatment with curcumin analogs, while our study found an approximately $60 \%$ of reduction [44]. Tumor burden decrease and survival rate increase were also found in mice-bearing breast cancer after DM1 treatment in combination with paclitaxel chemotherapeutic [15].

In conclusion, the molecular and cellular mechanisms related to tumor cell death after DM-1 treatment compared to the currently used chemotherapeutic agent, DTIC, have been presented. Here, we confirm the high toxicity and nonspecificity of DTIC when used for tumor treatment. Moreover, these results show that DM-1 induces tumor cell apoptosis through both the extrinsic and intrinsic pathways, and DM-1 treatment also causes cell cycle arrest. In vivo antitumor therapy showed high synergism between DTIC and DM-1 may help side effects decrease during melanoma treatment. These data confirm DM-1 as a powerful chemotherapeutic agent with effective tumor control properties and a lower incidence of side effects in normal cells compared to DTIC.

\section{Acknowledgments}


The authors are grateful to Fundação de Amparo à Pesquisa do Estado de São Paulo (Fapesp 2008/56397-8, 2008/58817-4 and 2011/50435-8), the Spanish government and the European Union (FIS-PI10/00338) for financial support.

\section{References}

1. Garbe C, Leiter U. Melanoma epidemiology and trends. Clin Dermatol. 2009;27:3-9.

2. Jilaveanu LB, Aziz SA, Kluger HM. Chemotherapy and biologic therapies for melanoma: do they work? Clin Dermatol. 2009;27:614-25.

3. Siegel R, Naishadham D, Jemal A. Cancer statistics. CA Cancer J Clin. 2012;62:10-29.

4. Schadendorf D, Ugurel S, Schuler-Thurner B, Nestle FO, Enk A, Bröcker EB, Grabbe S, Rittgen W, Edler L, Sucker A, Zimpfer-Rechner C, Berger T, Kamarashev J, Burg G, Jonuleit H, Tüttenberg A, Becker JC, Keikavoussi P, Kämpgen E, Schuler G. DC study group of the DeCOG. Dacarbazine (DTIC) versus vaccination with autologous peptide-pulsed dendritic cells (DC) in first-line treatment of patients with metastatic melanoma: a randomized phase III trial of the DC study group of the DeCOG. Ann Oncol. 2006;17:563-70.

5. Eigentler TK, Caroli UM, Radny P, Garbe C. Palliative treatment of disseminated malignant melanoma: a systemic review of 41 randomised clinical trials. Lancet Oncol. 2003;4:748-59.

6. Straussman R, Morikawa T, Shee K, Barzily-Rokni M, Qian ZR, Du J, Davis A, Mongare MM, Gould J, Frederick DT, Cooper ZA, Chapman PB, Solit DB, Ribas A, Lo RS, Flaherty KT, Ogino S, Wargo JA, Golub TR. Tumour micro-environment elicits innate resistance to RAF inhibitors through HGF secretion. Nature 2012; 487:500-4

7. Dean E, Lorigan P. Advances in the management of melanoma: targeted therapy, immunotherapy and future directions. Expert Rev Anticancer Ther. 2012;12:1437-48.

8. Rudolph BM, Groffik A, Stanger C, Loquai C, Grabbe S. Systemic therapy for malignant melanoma. Hautarzt. 2012;63:885-98.

9. Lillehammer T, Engesaeter BO, Prasmickaite L, Maelandsmo GM, Fodstad O, Engebraaten O. Combined treatment with Ad-hTRAIL and DTIC or SAHA is associated with increased mitochondrial-mediated apoptosis in human melanoma cell lines. J Gene Med. 2007;9:440-51.

10. Carvalho FR, Vassão RC, Nicoletti MA, Maria DA. Effect of Curcuma zedoaria crude extract against tumor progression and immunomodulation. J Venom Anim Toxins Incl Trop Dis. 2010;16:324-41. 
11. Abusnina A, Keravis T, Yougbaré I, Bronner C, Lugnier C. Anti-proliferative effect of curcumin on melanoma cells is mediated by PDE1A inhibition that regulates the epigenetic integrator UHRF1. Mol Nutr Food Res. 2011;55:1677-89.

12. Rivera-Espinoza Y, Muriel P. Pharmacological actions of curcumin in liver diseases or damage. Liver Int. 2009;29:1457-66.

13. Bisht S, Maitra A. Systemic delivery of curcumin: 21st century solutions for an ancient conundrum. Curr Drug Discov Technol. 2009;6:192-9.

14. Shoba G, Joy D, Joseph T, Majeed M, Rajendran R, Srinivas PS. Influence of piperine on the pharmacokinetics of curcumin in animals and human volunteers. Planta Med. 1998;64:353-6.

15. Faião-Flores F, Suarez JA, Pardi PC, Maria DA. DM-1, sodium 4-[5-(4-hydroxy-3-methoxyphenyl)-3-oxopenta-1,4-dienyl]-2-methoxy-phenolate: a curcumin analog with a synergic effect in combination with paclitaxel in breast cancer treatment. Tumour Biol. 2012;33:775-85.

16. Faião-Flores F, Pardi PC, Santos RP, Rando DG, Quincoces, JAP, Maria DA. Antiproliferative and antimetastatic activity of DM-1, sodium 4-[5-(4-hydroxy-3-methoxyphenyl)-3-oxo-penta-1,4-dienyl]-2methoxy-phenolate, in B16F10 melanoma. Applied Cancer Res. 2008;28:72-9.

17. Brohem CA, Massaro RR, Tiago M, Marinho CE, Jasiulionis MG, de Almeida RL, Rivelli DP, Albuquerque RC, de Oliveira TF, de Melo Loureiro AP, Okada S, Soengas MS, de Moraes Barros SB, Maria-Engler SS. Proteasome inhibition and ROS generation by 4-nerolidylcatechol induces melanoma cell death. Pigment Cell Melanoma Res. 2012;25:354-69.

18. Quincoces Suarez JA, Rando DG, Maria DA, Pardi P, Martins C, De Souza P. Methods to prepare penta-1,4dien-3-ones and substituted cyclohexanones and derivatives and derivatives with antitumoral and antiparasitic properties, the compounds and their uses. Brazilian Patent PI 0602640-0 (06.07.2006); PCT/ BR2007/000175 (06.07.2007); WO 2008/003155.

19. Quincoces Suarez JA, Maria DA, Faião-Flores F, Rando DG, Santos RP, Pardi P. Pharmaceutical composition and use of the pharmaceutical composition for the treatment, prophylaxis or prevention of neoplastic diseases in human and animals. Brazilian Patent: PI 0902039-0; 09/06/2009; PCTBR2009/000375; 11.11.2009; WO 2010/142007; 16/12/2010.

20. Quincoces Suarez J, Rando DG, Santos RP, Gonçalves CP, Ferreira E, Carvalho J, Kohn L, Maria DA, Faião-Flores F, Michalik D, Marcucci MC, Vogel C. New antitumoral agents I: In vitro anticancer activity and in vivo acute toxicity of synthetic 1,5-bis(4-hydroxy- 3-methoxyphenyl)-1,4-pentadien-3-one and derivatives. Bioorg Med Chem. 2010;18:6275-81. 
21. Mosmann T. Rapid colorimetric assay for cellular growth and survival: application to proliferation and cytotoxicity assays. J Immunol Methods. 1983;65, 55-63.

22. Ohkawa H, Ohishi N, Yagi K. Assay for lipid peroxides in animal tissues by thiobarbituric acid reaction. Anal Biochem. 1979;95:351-8.

23. Cheng X, Xiao Y, Wang X, Wang P, Li H, Yan H, Liu Q. Anti-tumor and pro-apoptotic activity of ethanolic extract and its various fractions from Polytrichum commune L.ex Hedw in L1210 cells. J Ethnopharmacol. 2012. $143(1): 49-56$.

24. Brasil. Ministério da Saúde. Memento terapêutico 2007/2008. 2nd ed. Brasília; 2007.

25. Geran RI, Greenberg NH, Macdonald MM, Schumacher AM, Abbott BJ. Protocols for screening chemical agents and natural products against animal tumors and other biological systems, 3rd ed. National Institute of Health, Bethesda; 1972. pp. 47-51

26. Henmi K, Hiwatashi Y, Hikita E, Toyama N, Hirano T. Methoxy- and fluoro-chalcone derivatives arrest cell cycle progression and induce apoptosis in human melanoma cell A375. Biol Pharm Bull. 2009;32:1109-13.

27. Chen Y, Kramer DL, Diegelman P, Vujcic S, Porter CW. Apoptotic signaling in polyamine analogue-treated SK-MEL-28 human melanoma cells. Cancer Res. 2001;61:6437-44.

28. Li W, Sanki A, Karim RZ, Thompson JF, Soon Lee C, Zhuang L, McCarthy SW, Scolyer RA. The role of cell cycle regulatory proteins in the pathogenesis of melanoma. Pathology. 2006;38:287-301.

29. Ladstein R, Bachmann I, Straume O, Akslen LA. Ki-67 expression is superior to mitotic count and novel proliferation markers $\mathrm{PHH}$, MCM4 and mitosin as a prognostic factor in thick cutaneous melanoma. BMC Cancer. 2010;10:140.

30. Eberle J, Kurbanov BM, Hossini AM, Trefzer U, Fecker LF. Overcoming apoptosis deficiency of melanomahope for new therapeutic approaches. Drug Resist Updat. 2007;10: 218-234.

31. Srinivasan M, Sudheer AR, Rajasekaran KN, Menon VP. Effects of curcumin analog on gamma-radiationinduced cellular changes in primary culture of isolated rat hepatocytes in vitro. Chem Biol Interact. 2008;176:18.

32. Jagetia GC, Reddy TK. Modulation of radiation induced alterations in the antioxidant status of mice by naringin. Life Sci. 2005;77:780-94. 
33. Benzie IF. Lipid peroxidation: a review of causes, consequences, measurement and dietary influences. Int $\mathbf{J}$ Food Sci Nutr. 1996;47:233-261.

34. Heiskanen KM, Bhat MB, Wang HW, Ma J, Nieminen AL. Mitochondrial depolarization accompanies cytochrome c release during apoptosis in PC6 cells. J Biol Chem. 1999;274:5654-8.

35. Tait SWG, Green DR. Mitochondria and cell death: outer membrane permeabilization and beyond. Nature Reviews Molecular Cell Biology. 2010.11: 621-32.

36. Mellier G, Huang S, Shenoy K, and Pervaiz S. TRAILing death in cancer. Mol Aspects Med. 2010;31:93112.

37. Du CY, Fang M, Li YC, Li L, Wang XD. Smac, a mitochondrial protein that promotes cytochrome cdependent caspase activation by eliminating IAP inhibition. Cell. 2000;102:33-42.

38. Riedl SJ, Shi Y. Molecular mechanisms of caspase regulation during apoptosis. Nat Rev Mol Cell Biol. 2004;5:897-907.

39. Bill MA, Fuchs JR, Li C, Yui J, Bakan C, Benson DM Jr, Schwartz EB, Abdelhamid D, Lin J, Hoyt DG, Fossey SL, Young GS, Carson WE 3rd, Li PK, Lesinski GB. The small molecule curcumin analog FLLL32 induces apoptosis in melanoma cells via STAT3 inhibition and retains the cellular response to cytokines with anti-tumor activity. Mol Cancer. 2010;9:165.

40. Piro LD. Apoptosis, Bcl-2 antisense, and cancer therapy. Oncology (Williston Park); 2004 18:5-10.

41. Lebe B, Pabuççuoğlu U, Ozer E. The significance of Ki-67 proliferative index and cyclin D1 expression of dysplastic nevi in the biologic spectrum of melanocytic lesions. Appl Immunohistochem Mol Morphol.2007;15:160-4.

42. Linden MD, Torres FX, Kubus J, Zarbo RJ. Clinical application of morphologic and immunocytochemical assessments of cell proliferation. Am J Clin Pathol. 1992; 97:S4-13.

43. Al-Hujaily EM, Mohamed AG, Al-Sharif I, Youssef KM, Manogaran PS, Al-Otaibi B, Al-Haza'a A, AlJammaz I, Al-Hussein K, Aboussekhra A. PAC, a novel curcumin analogue, has anti-breast cancer properties with higher efficiency on ER-negative cells. Breast Cancer Res Treat. 2011;128:97-107.

44. Aggarwal S, Ndinguri MW, Solipuram R, Wakamatsu N, Hammer RP, Ingram D, Hansel W. [DLys(6)]luteinizing hormone releasing hormone-curcumin conjugate inhibits pancreatic cancer cell growth in vitro and in vivo. Int J Cancer. 2011;129:1611-23. 


\section{Legends}

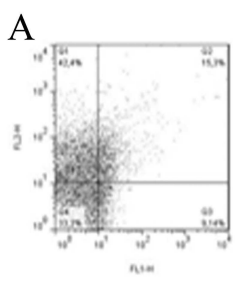

$\mathrm{D}$

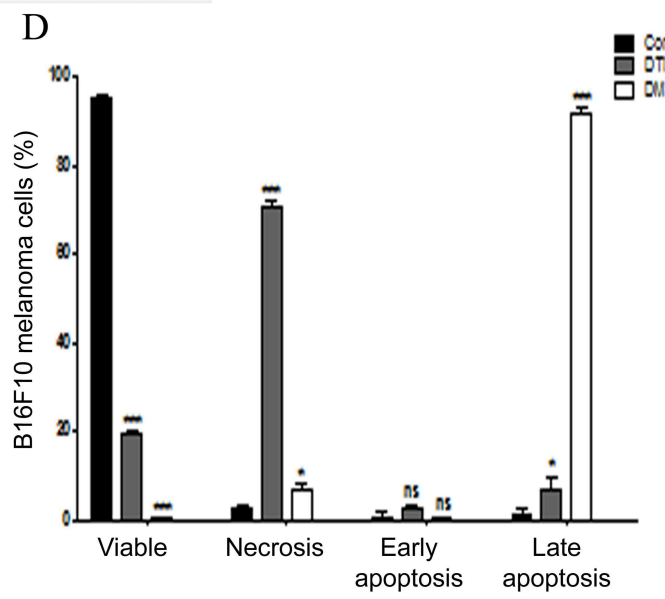



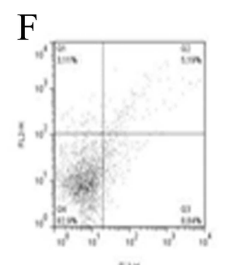

$\mathrm{H}$

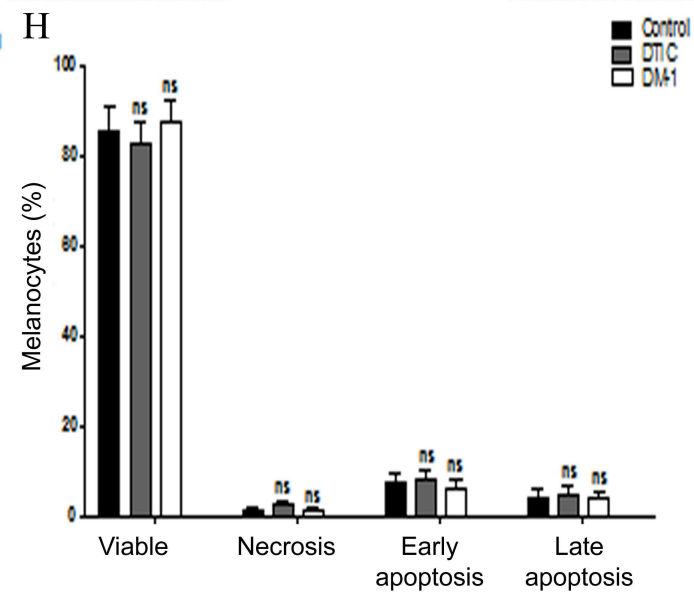

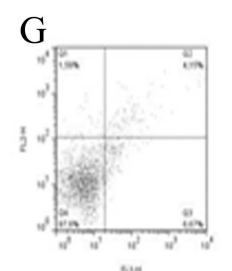

Figure 1 - Representative histograms of B16F10 melanoma cells (A) control, (B) DTIC, (C) DM-1 and melanocytes (E) control, (F) DTIC, (G) DM-1 stained with annexin-V (FL-1H axis X) and propidium iodide (FL-2H axis $\mathrm{Y}$ ) for cell death quantification. The distribution (mean \pm s.d.) is the number of viable, necrotic and apoptotic (D) B16F10 melanoma cells and (G) melanocytes.

ns: not significant compared to the control.

$* \mathrm{p}<0.05$ and $* * * \mathrm{p}<0.001$ compared to control.

A



B

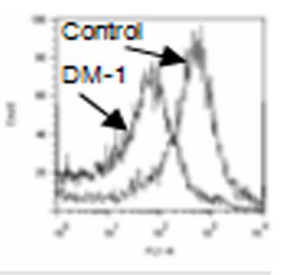

D

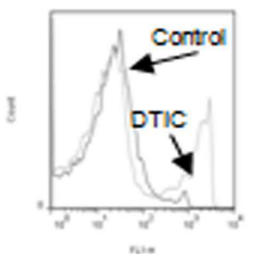

E

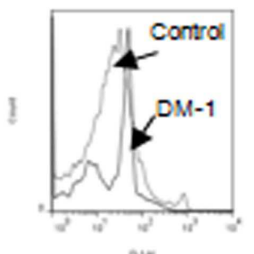

Active/Viable
Inactive/lnviable

$\mathrm{C}$
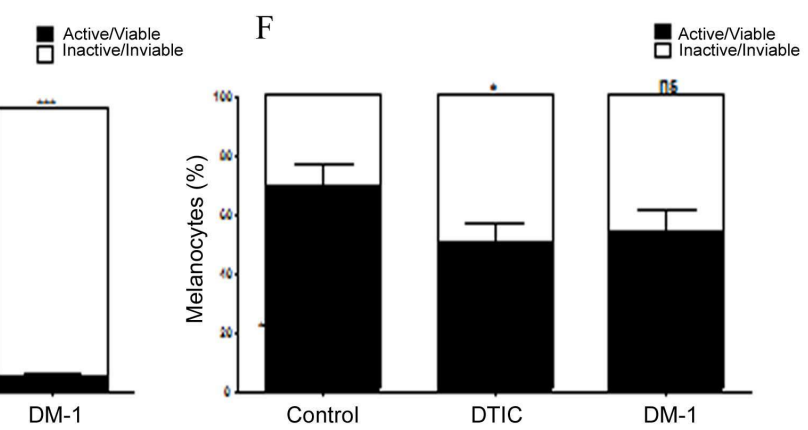

Figure 2 - Representative overlaps of fluorescence intensity from melanoma cells and normal melanocytes stained with Rhodamine 123 and analyzed by flow cytometry. The overlaps represent the B16F10 melanoma cells treated with (A) DTIC and (B) DM-1 and the melanocytes treated with (D) DTIC and (E) DM-1. The 
distribution (mean \pm s.d.) is the number of (C) B16F10 melanoma cells and (F) melanocytes with active mitochondria (viable cells) or inactive mitochondria (inviable cells).

ns: not significant compared to the control.

$* \mathrm{p}<0.05$ and $* * * \mathrm{p}<0.001$ compared to the control.



Figure 3 - Detection of apoptotic cells by Hoechst 33342 staining. A375 human melanoma cells (A) control and treated for $24 \mathrm{~h}$ with (B) DTIC ( $\left.\mathrm{IC}_{50}-548 \mu \mathrm{M}\right)$, (C) DM-1 ( $\left.\mathrm{IC}_{50}-65 \mu \mathrm{M}\right)$ or (D) a combination of DTIC (5 $\mu \mathrm{M})+\mathrm{DM}-1(5 \mu \mathrm{M})(400 \mathrm{x}$ magnification). The inset represents the cell confluence (100x magnification).

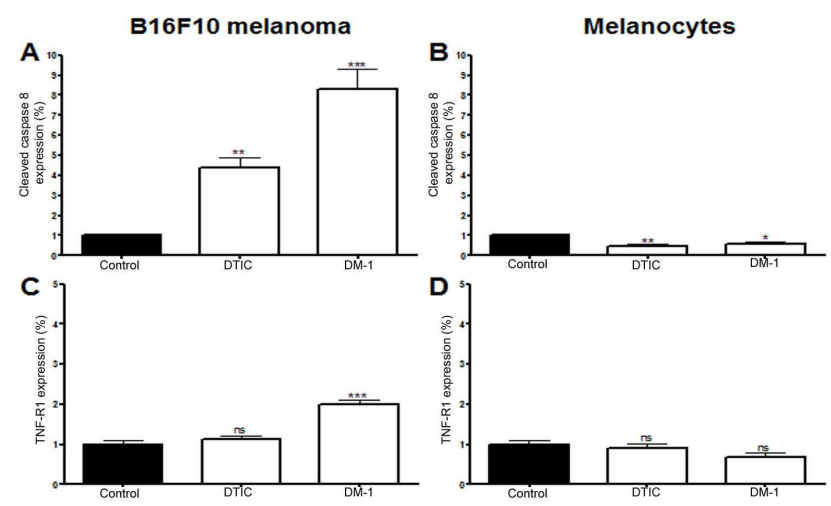

Figure 4 - Expression of apoptotic markers in melanoma cells and normal melanocytes (normalized values of the mean \pm s.d.) by flow cytometry. Cleaved caspase 8 expression after DTIC and DM-1 treatment compared to the control in (A) B16F10 melanoma cells and (B) melanocytes. TNF-R1 expression after DTIC and DM-1 treatment compared to the control in (C) B16F10 melanoma cells and (D) melanocytes.

ns: not significant compared to the control.

$* \mathrm{p}<0.05, * * \mathrm{p}<0.01$, and $* * * \mathrm{p}<0.001$ compared to the control. 
A

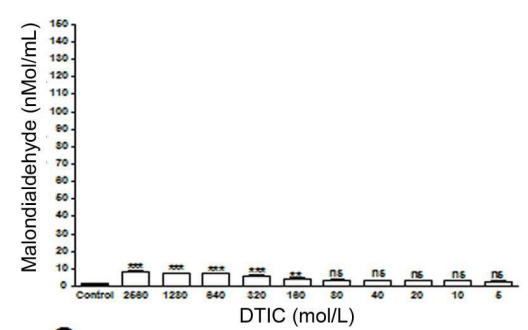

C



B
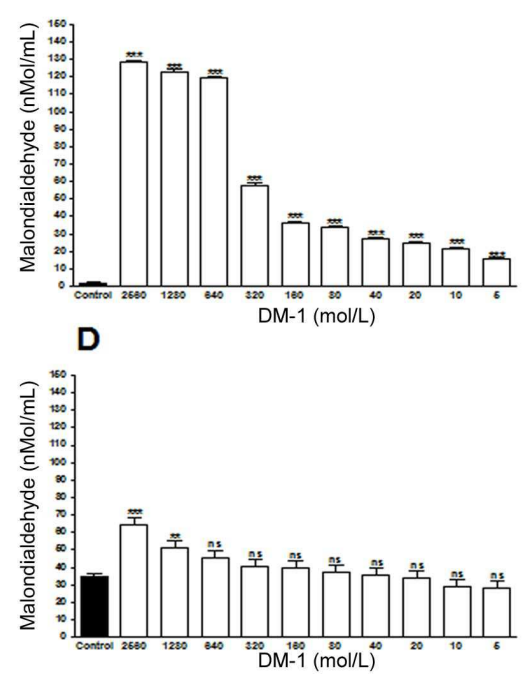

Figure 5 - Malondialdehyde production after DTIC (A) and DM-1 (B) treatment in B16F10 melanoma cells, and (C) DTIC and (D) DM-1 treatment in melanocytes at different concentrations compared to the control. ns: not significant compared to the control.

$* * \mathrm{p}<0.01$ and $* * * \mathrm{p}<0.001$ compared to the control.
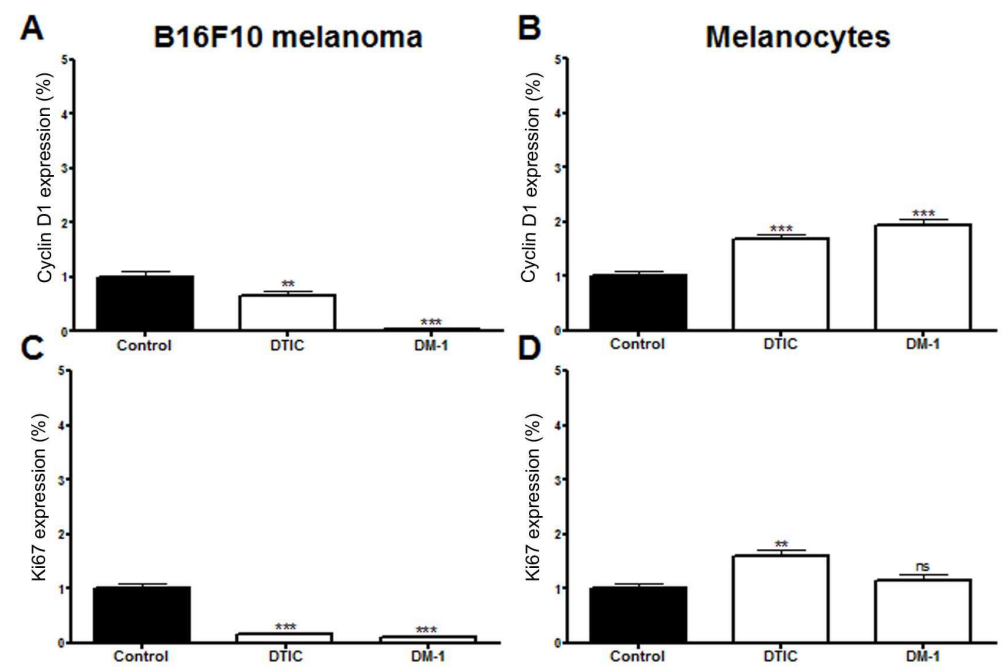

Figure 6 - Expression of cell cycle regulator markers in melanoma cells and normal melanocytes (normalized values of the mean \pm s.d.) by flow cytometry. Cyclin D1 expression after DTIC and DM-1 treatment compared to the control in (A) B16F10 melanoma cells and (B) melanocytes. Ki67 expression after DTIC and DM-1 treatment compared to the control in (C) B16F10 melanoma cells and (D) melanocytes.

ns: not significant compared to the control.

$* * \mathrm{p}<0.01$, and $* * * \mathrm{p}<0.001$ compared to the control. 



Figure 7 - Tumor growth of mice bearing B16F10 melanoma after DTIC, DM-1 or DTIC+DM-1 treatment in comparison to control group. (A) Tumor area measurements were obtained subsequent to the 14th day of tumor inoculation during 14 treatment days. The tumor burden is represented next to each respective treatment line. The values are expressed as mean \pm s.d.; (B) Survival rate of mice bearing B16F10 melanoma subsequent to the 14th day of tumor inoculation during 14 treatment days. Significance is indicated by: ***p<0.001 compared to control; \&p<0.05 to compare DTIC+DM-1 and DM-1 groups; \#\#\#p<0.001 to compare DTIC+DM-1 and DTIC groups. 